as to my eligibility, as did several Oxford graduates to whom it was shown. I shall presently refer to Prof, Clifton's "warning."

The examination was to begin on Oct. 7 , at 9 A.M. On presenting myself, a gentleman whose name I do not know, told me that the Physics papers would not be given out before Oct. 10, that if I felt inclined to work the paper given to candidates for the Mathematical Fellowship I might do so, and credit would be given for Mlathematics in the even: of two men being equal in the Physics examination. I shall not comment on this promising arrangement, or on the fact that the candidates for the Physics fellow. ship had not till then heard of the Mathematical paper. Our informant told me that there were grave doubts as to the eligibility of outsiders. He certainly gave me to understand that these doubts extended to all who were not Oxford graduates. I understood that some Cambridge men had presented themselves also ; that the question of our eligibility was about to be settled with the Registrar of the Univcrsity, and that if I called on the Warden between four and five in the afternoon (the time mentioned in the original notice) he would be provided with the results of the deliberations.

At 4.30 I found the Varden about to go away somewhere. I had an audience of about two minutes; was asked what College I belonged to (meaning in Oxford). - Not an Oxford man, I answered.-Then he was afraid I was ineligible. I then informed him that I was the graduate of the Queen's University, to whom he had written in June. I suppose he had very little time for apologies, but he let me linow, before leaving, that he had misinterpreted the results of some late commission when he wrote in June, and that I need have no hope.

I have staled the grounds for my former general statement. If Prof. Clifton is certain that graduates of Dublin and Cam. bridge are eligible, we must rely on his information being most correct, but $1 \mathrm{am}$ troubled to know who is answerable for my being left in ignorance until now, and if anybody knows whether elections are never made of men who would really be ineligible by the laws of the University.

2. He insinuates a deception on my part, in not mentioning his "waming." I take it that Prof. Clifton has partly forgotten the matter of which he speaks. I wrote to him for leave to in spect the Physical Laboratory at Oxford, not certain that he was one of the examiners, but aware that he had charge of that institution and that the examination must be held there (see 3 ). I did not speak of my elioibility.

There is no doubt about the fact that great difficulties are thrown in the way of outsiders, but I should have been wrong if I had laid any blame on Prof. Clifton for taking the only course open to him. The case is simply this : accurding to the present Physics arrangements at Oxford, outsiders preparing for the October Fellowship examination at Merton cousd not without giving the greatest imaginable trouble to Prof. Clifton get any opportunity of inspecting the apparatus.

After stating that he was unable to afford me the desired opportunity, he asked if I had ascertained about my eligibility, inform. ming me that the warden or sub-warden was the proper person to apply to. I immediately wrote that I had alritudy made such an inquiry, stating the result.

I now infer that he, after receiving my letter and aware that I had made the proper inquiries, allowed both the Warden and myself to remain in ignorance of the grievous mistake. On receiving no answer I lelt perfectly certain that the information received from the Warden was correct.

When I last wrote to NATURE I feit grateful to Prof. Chifton for his inquiry, incomplete and worse than useless "warning" as it had been. Surely no one will think that I had any right to introduce his name.

3. He says it was by no means certain that the Practical Physics examination would be held in the Physical Laboratory. Will he assert that in any one of the nineteen colleges of which he speaks, or in the nineteen collectively there is apparatus for conducling such an examination?

He wonders why it should be necessary to inspect the particular apparatus to be employed in the examination. I do not know if Prof. Clifton was really one of the examiners for the fellowship, but surely he cannot have thought about the matter without being aware of the immense importance of a previous acquaintance with the apparatus such as Oxford men are sure to have. I heard by accident in July that there was no delicate apparatus, nor were proper arrangements made for exact experiments in Stalic Electricity. Can Prof. Clifton not understand that to an outsider such information might be of the greatest importance.
"What arrangement of telescope stand is there for measuring wave-lengths?" "Is there a Soleil's instrument for measuring the angle between the axes in biaxial crystals?" "Will the arrangements for observing deflections of a needle enable us to employ the logarithmic decrement?" These questions and a hundred others as important were constantly distracting me during the four months of preparation.

My letter to Prof. Clifton was, I believe, modest, and showed my respect for him as a man who had done a great work in his attempt to create a Physics School at Oxford. My request was not "unreasonable." I did not know that his presence was necessary during an inspection of the Physical Cabinet, or the University. I maintain too, that be has no right to assert that I must feel very uncertain about my own practical knowledge.

London, Ost. $2 S$

JOIIN PERRY

\section{Simple Diffraction Experiment}

TIIE apparatus for this experiment consists of a slit and $a$ grating. A slit may be made by ruling a line on a piece of smoked glass. The grating is made by slightly greasing the thumb and forefinger (there is naturally sufficient on the hot and moist hand), and by drawing a piece of clean glass through them so as to obtain alternate parallel light spaces and greasy lines on both sides of the glass; out of several trials a grating may be made which when used in the following manner will give very pretty results.

The grating being placed close to the eyc, the slit (with its direction parallel to that of the lines on the grating) is held up before some bright light, as of a candle, and looked at, as if the grating did not exist. Very beautiful and numerous spectra may then be seen ranged on each side of the slit.

The vitreous surface of window glass does not seem to give such good gratings as a worked and polished surface, as for instance that of a weak spectacle lens.

Oxford

II. L.

\section{Publication of Learned Societies' Transactions}

IN NATURE, vol. viii. p. $506 \mathrm{Mr}$. Röhrs wishes that our learned societies would publish their papers separately. I have urged this before in NATURE, but unsuccessfully. With Transactions such as those of the Royal Society, the present system is almost an ab. surdity, for papers on most incongruous subjects are bound up together, and the cost is too great. When once a paper is printed, the Council seem to think that there is nothing more to be done, and do not in any way try to make the work kifown. All papers should be sold separately as cheaply as possible, and on publication, should be advertised in the scientific journals.

If this were done, we should not have men like Prof. Sylvester writing as follows :- "I owe my thanks to M. Radau and the editor of the Annals of the Ecole Normale Superieure for having been at the pains to disentomb the little known conclusions contained therein from their honourable place of sepulturc in the Philosophical Transactions." IV. B. Gibss

\section{EXAMINATIONS OF THE SCIENCE AND ART}

\section{DEPARTIENT IN BIOLOGY}

THE syllabus of the Biological subjects in which examinations are held by the Science and Art Department, has undergone considerable modifications in the edition of the Directory which has been recently issued. Animal Physiology, Elementary Botany(including Flowering Plants only), are subjects which at present appear to be best adapted for the purposes of school instruction. They stand, therefore, in no necessarily logical relation to the other two which are grouped together under the head of General Biology. These involve the use of the compound microscope, and some amount of microscopic manipulation. They are therefore better fitted for rather more advanced, or at any rate, older students than the first stages of the subjects first mentioned. 